\title{
Optimization of process-property relations of 3D printed ceramics using extrusion-based additive manufacturing
}

\author{
Muhammad Asad Farid, Matteo Strano and Kedarnath Rane
}

Muhammad Asad Farid. Dipartimento di Meccanica. Politecnico di Milano, Via Lasa Masa 1, Milan, Italy. Corresponding author:

Muhammad Asad Farid. E-mail address: muhammadasad.farid@polimi.it

Matteo Strano. Dipartimento di Meccanica. Politecnico di Milano, Via Lasa Masa 1, Milan, Italy

Kedarnath Rane. Dipartimento di Meccanica. Politecnico di Milano, Via Lasa Masa 1, Milan, Italy

Abstract. The capability and applicability of additive manufacturing have mesmerized the entire manufacturing world. One major technique of additive manufacturing is extrusion-based additive manufacturing (EAM), which has been recently employed for the rapid production of ceramic components, among other applications. This study focused on establishing the process-property relations for extrusion-based additively manufactured ceramics, namely Alumina $\left(\mathrm{Al}_{2} \mathrm{O}_{3}\right)$ and Zirconia $\left(\mathrm{ZrO}_{2}\right)$, and then optimization of the relations to get the desired mechanical properties for applicability. Extrusion-based additive manufacturing was used to obtain the ceramic sample parts from ceramic-binder mixtures and by subsequent post-processing. The process parameters chosen for the study were extrusion velocity and part orientation whereas the mechanical properties selected were hardness and flexural strength. Extrusion velocity was varied at three levels i.e. $7.5 \mathrm{~mm} / \mathrm{s}, 12.5 \mathrm{~mm} / \mathrm{s}$ and $17.5 \mathrm{~mm} / \mathrm{s}$. Two levels selected for part orientation were horizontal and vertical. The design of experiments technique was used to establish the process-property relations by highlighting the most significant process parameters affecting the selected mechanical properties. Optimization was achieved by highlighting those levels of significant process parameters that provided the desired values of mechanical properties. Part orientation came out to be a significant factor affecting both the hardness and flexural strength of the two ceramics whereas extrusion velocity was found to be insignificant for both mechanical properties. Among the two levels of part orientation, vertical orientation samples showed higher values of hardness while horizontal samples showed higher flexural strength thus, aiding in the optimization of the process-property relations.

Keywords. Alumina, Zirconia, Ceramics, Hardness, Flexural Strength, Additive Manufacturing, Optimization, Process, Property, Extrusion, 3D printing

\section{Introduction}

The additive manufacturing techniques are rapidly being employed for 3D printing ceramics and their utilization is predicted to increase soon [1]. This is essentially true for slurry-based processes and selective laser sintering [2,3]. Engineering ceramics have been known to possess various valuable properties like high hardness, stiffness, and corrosion resistance just to name a few. Alumina $\left(\mathrm{Al}_{2} \mathrm{O}_{3}\right)$ exhibit excellent thermal and mechanical properties at high temperatures. Zirconia $\left(\mathrm{ZrO}_{2}\right)$ exhibits high toughness, thermal insulation, biocompatibility, and ionic conductivity $[4,5]$.

Once the ceramics have been printed, it is crucial to get the desired mechanical properties for the parts to be functional. Among these properties, hardness and flexural strength are of extreme importance specifically for alumina and zirconia. Several efforts have been made to predict the hardness and fracture toughness of alumina and zirconia using different compositions, different manufacturing technologies, and different procedures. The hardness of alumina has been determined by various researchers using Vickers indentation method and ranges between 1400-2100 HV. The hardness of zirconia depends on its relative density and on the addition of dopants [6]. An increase of relative density from $95 \%$ to $98 \%$ makes the hardness almost more than double. Zirconia stabilized by small percentages of Yttria increases its hardness significantly. The average Vickers hardness should be around $1337 \mathrm{HV}$. The flexural strength of dental alumina and zirconia were measured using a three-point bending test by Apholt and colleagues [7]. 
Optimization of process-property relations of 3D printed ceramics using extrusion-based...

Belenky and Rittel compared the static and dynamic flexural strength of $99.5 \%$ alumina [8]. The fracture toughness of yttria- stabilized tetragonal zirconia (Y-TZP) dental ceramics was determined by Ćorić et al. using Vickers indentation fracture test (VIF) [9].

Although different AM techniques can be used for 3D printing ceramics but this paper specifically focuses on extrusionbased additive manufacturing (EAM) of ceramics and process-property relations of 3D printed ceramics $\left(\mathrm{Al}_{2} \mathrm{O}_{3}\right.$ and $\mathrm{ZrO}_{2}$ ). EAM produces components at a high buildup rate and a lower cost per part in comparison with other AM techniques. The ability and versatility to additively manufacture a range of materials including metals, composites, and ceramics is a key advantage of EAM $[10,11]$. The final part quality and the material properties are affected by various parameters. These include material parameters (powder and binder properties), 3D printing process parameters, debinding, and sintering stages [12]. The most critical parameters as per the literature are shown in Fig. 1 but the process parameters selected for the study are extrusion velocity and part orientation and the selected properties are hardness and flexural strength because there is little to no literature relating extrusion-based 3D printing process parameters with the mechanical properties.

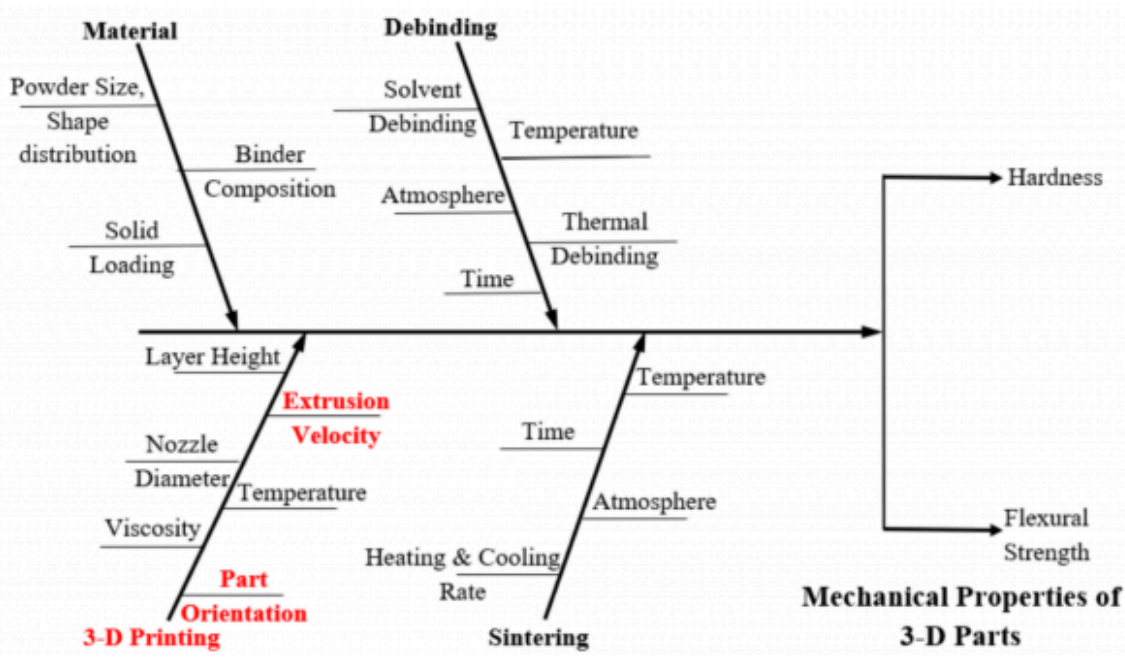

Fig. 1. Ishikawa Diagram of process parameters and properties of sintered EAM parts.

\section{Materials and Methods}

\subsection{Materials}

Commercially available feedstocks procured from Inmatech Technologies Gmbh in a palletized form (K1008 and K1009) for alumina and zirconia respectively were used in this study. The chemical composition for both ceramic powders is provided in Table 1 . The powders mainly consisted of $\mathrm{Al}_{2} \mathrm{O}_{3}$ and $\mathrm{ZrO}_{2}$ particles but for zirconia, $\mathrm{ZrO}_{2}$ powder was stabilized with 5.15 wt.\% Y203 (YSZ).

Table 1. Chemical composition of ceramic powders. 


\begin{tabular}{lllllll}
\hline Alumina & $\mathrm{Na} 2 \mathrm{O}$ & $\mathrm{MgO}$ & $\mathrm{CaO}$ & $\mathrm{Fe}_{2} \mathrm{O}_{3}$ & $\mathrm{SiO}_{2}$ & $\mathrm{Al}_{2} \mathrm{O}_{3}$ \\
wt.\% & $0.1 \%$ & $0.9 \%$ & $1.3 \%$ & $0.03 \%$ & $1.8 \%$ & $96 \%$ \\
\hline Zirconia & $\mathrm{Y}_{2} \mathrm{O}_{3}$ & $\mathrm{Al}_{2} \mathrm{O}_{3}$ & $\mathrm{SiO}_{2}$ & $\mathrm{Fe}_{2} \mathrm{O}_{3}$ & $\mathrm{NaO}_{2}$ & $\mathrm{ZrO}_{2}$ \\
Wt.\% & $5.15 \%$ & $0.25 \%$ & $0.02 \%$ & $0.01 \%$ & $0.04 \%$ & $94.5 \%$ \\
\hline
\end{tabular}

The binder elements were kept confidential by the supplier but the bulk volume of the binder was water-soluble and the left off polymeric binder could be removed by subsequent thermal debinding process. The ceramic-binder percentages by weight were $84.8 \% \mathrm{Al}_{2} \mathrm{O}_{3}$ and $15.2 \%$ binder for alumina and $84.2 \% \mathrm{ZrO}_{2}$ and $15.8 \%$ binder for zirconia respectively.

\subsection{D printing of ceramic parts}

The test samples were 3D printed using extrusion-based additive manufacturing (EAM) process. A specially designed machine called EFeSTO (Extrusion of Feedstock for the manufacturing of Sintered Tiny Objects) was used for this purpose as shown in Fig.2. Nozzles of different diameters were used for alumina and zirconia, $\mathrm{D}_{\mathrm{n}}=0.4 \mathrm{~mm}$ for alumina, and $D_{n}=0.8 \mathrm{~mm}$ for zirconia because zirconia showed inferior extrudability based on preliminary experiments carried out to test rheological characteristics of feedstock [13]. Samples were printed with a rectangular shape and had a cross-section of $6 \mathrm{~mm}$ height, $60 \mathrm{~mm}$ length, and 10 $\mathrm{mm}$ width respectively. The rectangular bars were printed in a "horizontal" orientation, laying on the face of dimensions 60 X $10 \mathrm{~mm}$, and "vertical" orientation, laying on the 60 X 10 $\mathrm{mm}$ face, to experiment with different layer orientations. For alumina feedstock, a total of 27 parts were printed with a nozzle of diameter $\left(\mathrm{D}_{\mathrm{n}}\right)$ of $0.4 \mathrm{~mm}$, extrusion temperature $\left(\mathrm{T}_{\mathrm{e}}\right)$ of $145^{\circ} \mathrm{C}$ and three different extrusion velocities $\left(\mathrm{V}_{\mathrm{e}}\right)$, as shown in Fig.3. Each experimental condition was replicated 3 times. Similarly, zirconia parts were 3D printed by employing the same experimental plan, but with $\mathrm{D}_{\mathrm{n}} 0.8 \mathrm{~mm}$ and extrusion temperature $\left(\mathrm{T}_{\mathrm{e}}\right)$ of $175^{\circ} \mathrm{C}$.

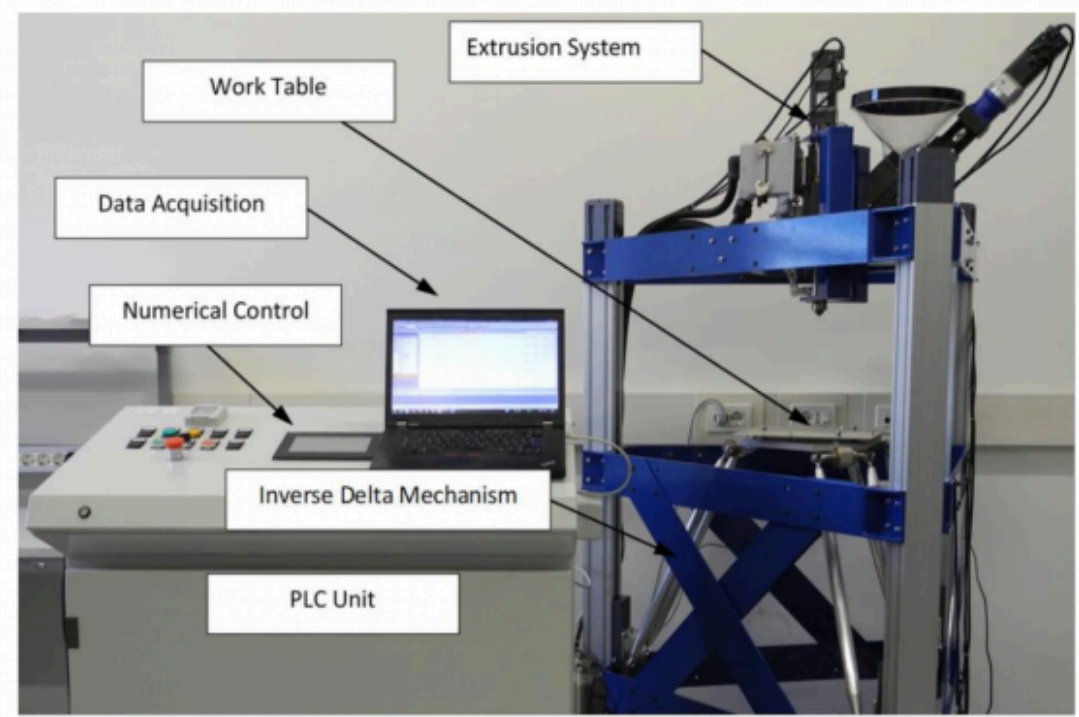

Fig. 2. EFeSTO Machine. 


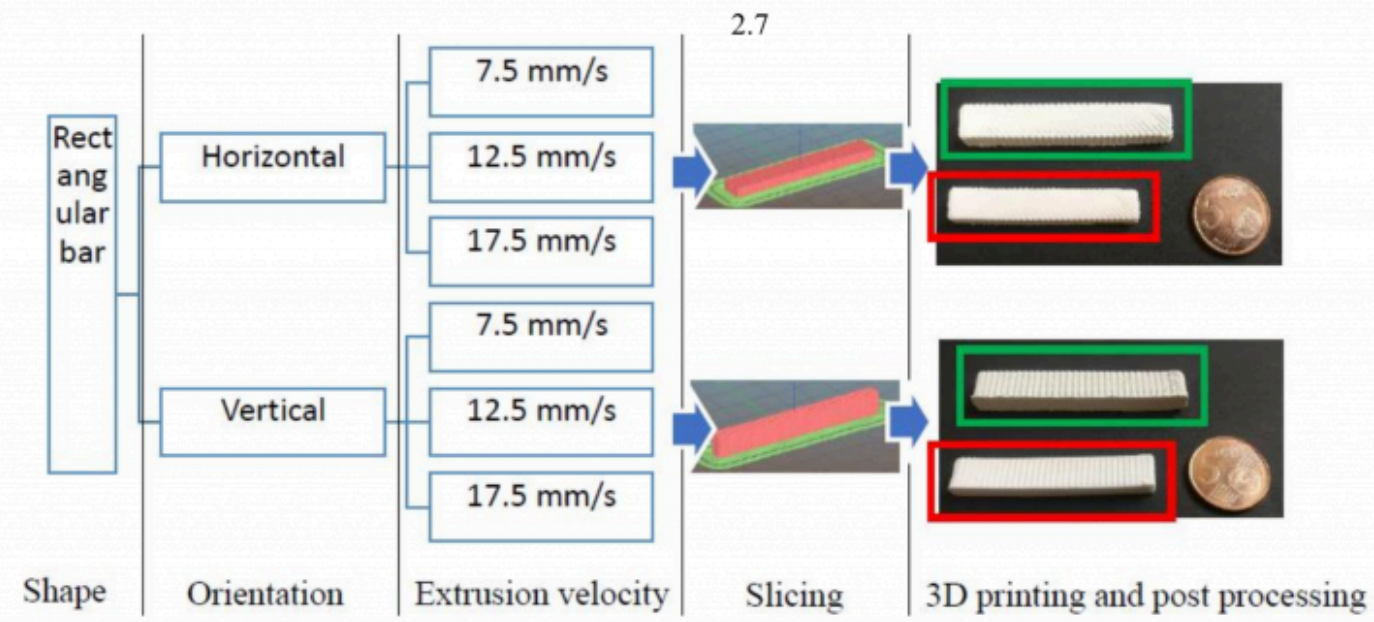

Fig. 3. Experimental plan of 3D printing.

\subsection{Post-Processing of 3D Printed Samples}

The samples obtained after 3D printing from EFeSTO, also called the green parts, required post-processing to remove the left-over binder. The debinding process consisted of two steps: solvent and thermal debinding respectively. Samples were solvent debinded in a bath of agitated water kept at $40{ }^{\circ} \mathrm{C}$ for 48 hours. This step carried out bulk removal of the binder however some binder was remaining and was removed by thermal debinding by heating the parts in an oven without any special atmosphere at a heating rate of $20^{\circ} \mathrm{C} / \mathrm{hr}$ up to a temperature of $145{ }^{\circ} \mathrm{C}$ with 4 hours hold time and then at a heating rate of $10{ }^{\circ} \mathrm{C} / \mathrm{hr}$ up to a temperature of $300{ }^{\circ} \mathrm{C}$ with 2 hours hold time, followed by natural cooling in the oven. The final sintering stage took place in an air atmosphere at a temperature of $1620^{\circ} \mathrm{C}$ for 1 hour for alumina and $1400{ }^{\circ} \mathrm{C}$ for 1 hour for zirconia. The increase to the sintering temperature was at a rate of $130{ }^{\circ} \mathrm{C} / \mathrm{hr}$ up to a temperature of $1500{ }^{\circ} \mathrm{C}$ and then at a rate of $40{ }^{\circ} \mathrm{C} / \mathrm{hr}$ up to $1620{ }^{\circ} \mathrm{C}$ for alumina parts. Whereas for zirconia parts, the increase to the sintering temperature was at a rate of $100^{\circ} \mathrm{C} / \mathrm{hr}$ up to a temperature of $1250^{\circ} \mathrm{C}$ and then at a rate of $40^{\circ} \mathrm{C}$.

\subsection{Characterization of 3D Printed Sample}

The mechanical properties selected for the study were Vickers hardness and flexural strength of the sintered samples. For this purpose, the samples were polished to obtain a smooth surface. In addition to orientation and $V_{e}$, hardness was tested by considering the face of the rectangular-shaped sample as an additional parameter with three levels: top, bottom, and side. The hardness of the parts was measured using a microhardness tester (FM-810, make: Future Tech) at $2 \mathrm{kgf}$ with a dwell time of $15 \mathrm{sec}$. The top and bottom face of horizontal part orientation was designated as $\mathrm{LH}_{\mathrm{H}} \mathrm{x} \mathrm{wH}_{\mathrm{H}}$ and the side face of horizontal part orientation was designated as $\mathrm{L}_{\mathrm{H}} \mathrm{x} \mathrm{w}_{\mathrm{H}}$ (Fig. 4). Similarly, the top and bottom face vertical part orientation was designated as $\mathrm{LV} \mathrm{x}$ wV and the side face of vertical orientation was designated as $\mathrm{LV} \mathrm{x} t \mathrm{~V}$. Where $\mathrm{L}_{\mathrm{H}}=\mathrm{LV}=60 \mathrm{~mm}, \mathrm{t}_{\mathrm{H}}=\mathrm{t}_{\mathrm{V}}=10 \mathrm{~mm}$ and $\mathrm{t}_{\mathrm{H}}=\mathrm{wV}_{\mathrm{V}}=6 \mathrm{~mm}$. 

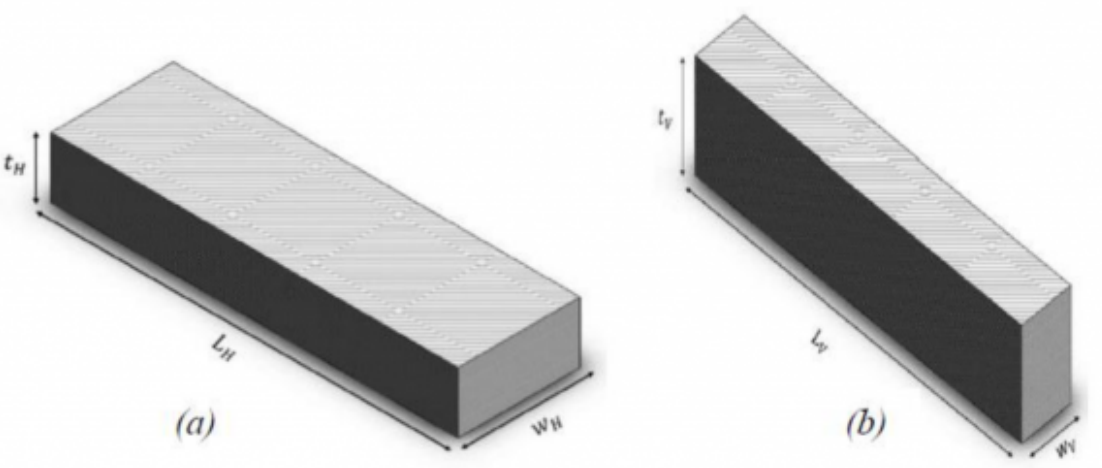

Fig. 4. Characterization of printing parameters and faces (a) horizontal orientation and (b) vertical orientation.

For flexural strength, a three-point bending test was performed on the samples using ASTM C1674-16 and ASTM A370-18 standards. The bending test was performed on MTS RT/150 machine. Simultaneous crosshead position (mm) was measured by acquiring deflections $(\mathrm{mm})$ using high accuracy deflectometer. All the tests were performed at room temperature under displacement control with a constant crosshead speed of $0.5 \mathrm{~mm} / \mathrm{min}$. The loading direction for both configurations was applied on the top face. The span length was set at $30 \mathrm{~mm}$. The reported values of hardness and flexural strength were the average of five and three measurements respectively taken from the 3D printed samples.

\section{Results and Discussion}

Design of experiments techniques were used for establishing and optimizing the process-property relations of the 3D printed ceramics. The general full factorial experiment analysis using multi-way ANOVA was performed at a $90 \%$ confidence interval.

\subsection{Vickers Hardness of the Ceramics}

Using ANOVA for both ceramics $\left(\mathrm{Al}_{2} \mathrm{O}_{3}\right.$ and $\left.\mathrm{ZrO}_{2}\right)$, it was observed that the printing orientation of the samples had a significant effect on the microhardness of the ceramics whereas the extrusion velocity showed little to no effect on the microhardness of the ceramics as can be seen in Fig. 5. 
Optimization of process-property relations of 3D printed ceramics using extrusion-based...

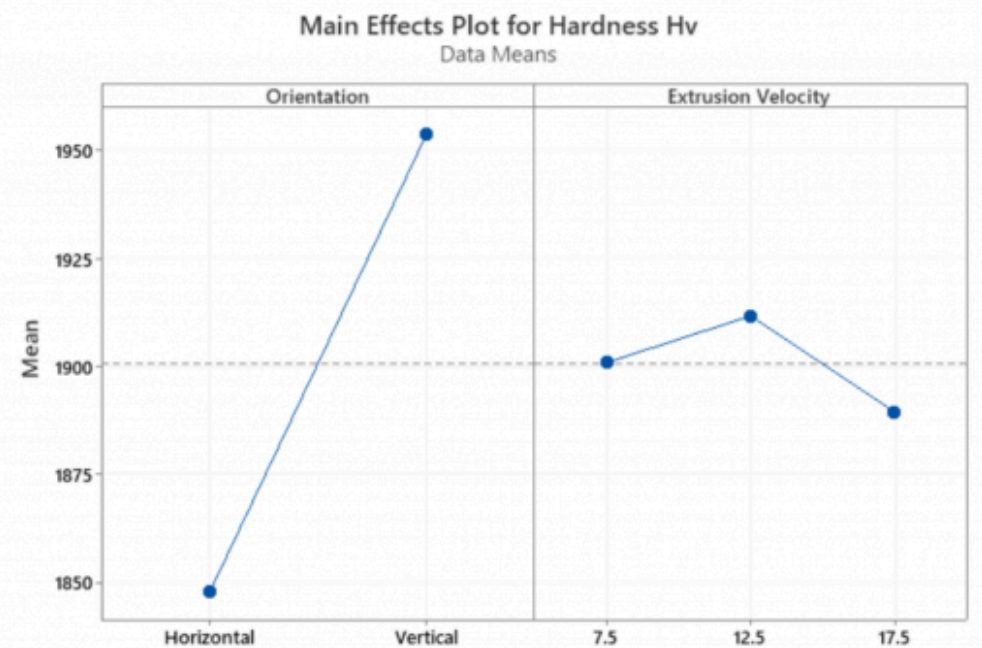

Fig. 5. Main effect plot indicating the significance of sample printing orientation for microhardness.

Furthermore, the vertical orientation samples showed higher hardness values as compared to the horizontal orientation samples. Also, within one orientation, the side face of the horizontal orientation samples $\left(L_{H} x t_{H}\right)$ and the top face ( $L V$ $\mathrm{x} t \mathrm{v}$ ) of the vertical orientation samples showed the maximum hardness values as shown in Fig. 6.
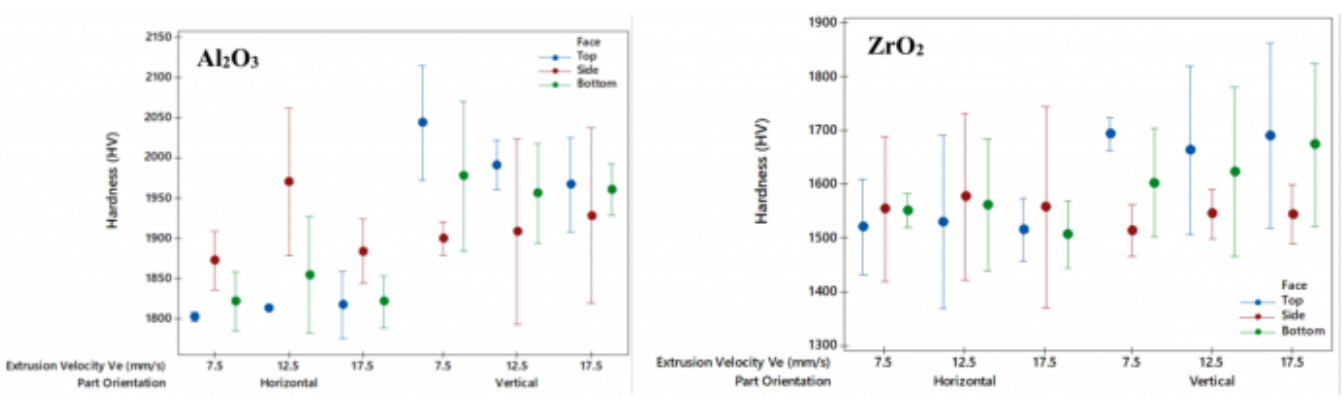

Fig. 6. Interval plots for both ceramics indicating the significance of vertical orientation for microhardness.

Since certain applications of ceramics require high values of hardness so optimization could be achieved by printing the samples in vertical printing orientation using extrusion-based additive manufacturing for maximizing the hardness of the ceramics.

\subsection{Flexural Strength of the Ceramics}

In order to calculate the flexural strength, stress values are required. These values were calculated from the loaddeflection data obtained from the three-point bending test using equation 1.

$$
\sigma=\frac{3 F L}{2 b t^{2}}
$$


where $\sigma=$ instantaneous stress (MPa), $\mathrm{F}=$ load $(\mathrm{kN})$, L is the span length (distance between center of two supporting pins) $(\mathrm{mm}), \mathrm{b}=$ width of the specimen $(\mathrm{mm}), \mathrm{t}=$ thickness of the specimen $(\mathrm{mm})$.

The flexural strength was then determined from the maximum value of the stress calculated using equation 1 . After calculating the flexural strength for all the samples for both ceramics, ANOVA was performed to establish the relations between part printing orientation and extrusion velocity with the flexural strength of the 3D printed samples. It was observed from ANOVA that the part printing orientation had a significant effect on the flexural strength of both ceramics while extrusion velocity had little to no effect on the flexural strength of both ceramics and showed no clear pattern as shown in Fig. 7.

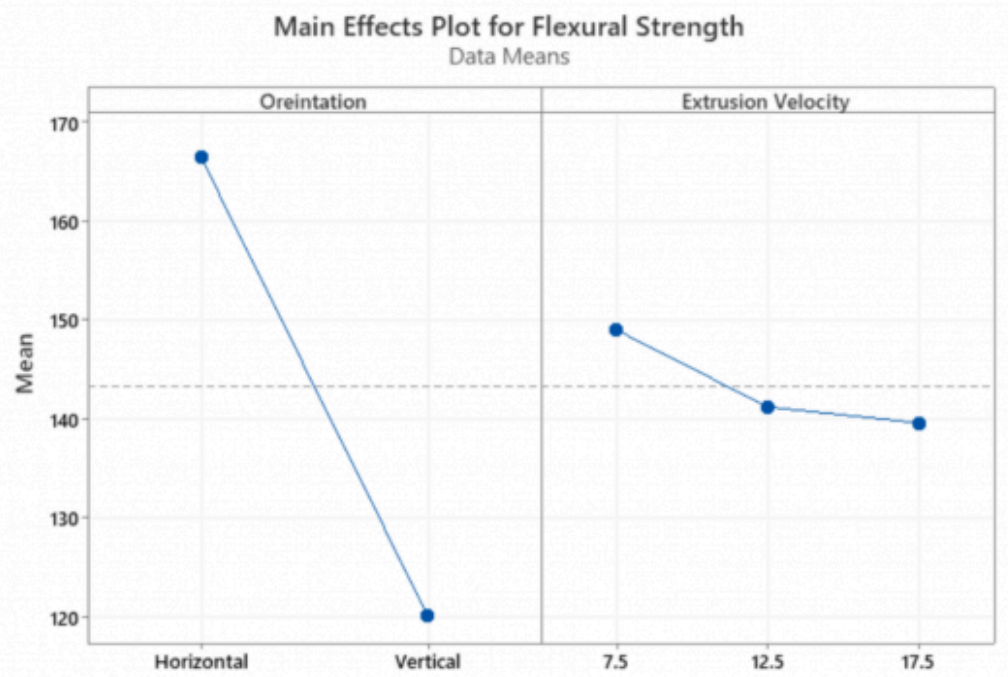

Fig. 7. Main effect plot indicating the significance of sample printing orientation for extrusion velocity.

Furthermore, it was observed that the horizontal orientation samples showed higher values of flexural strength as compared to the vertical orientation samples for both ceramics $\left(\mathrm{Al}_{2} \mathrm{O}_{3}\right.$ and $\left.\mathrm{ZrO}_{2}\right)$ as can be seen in Fig. 8.
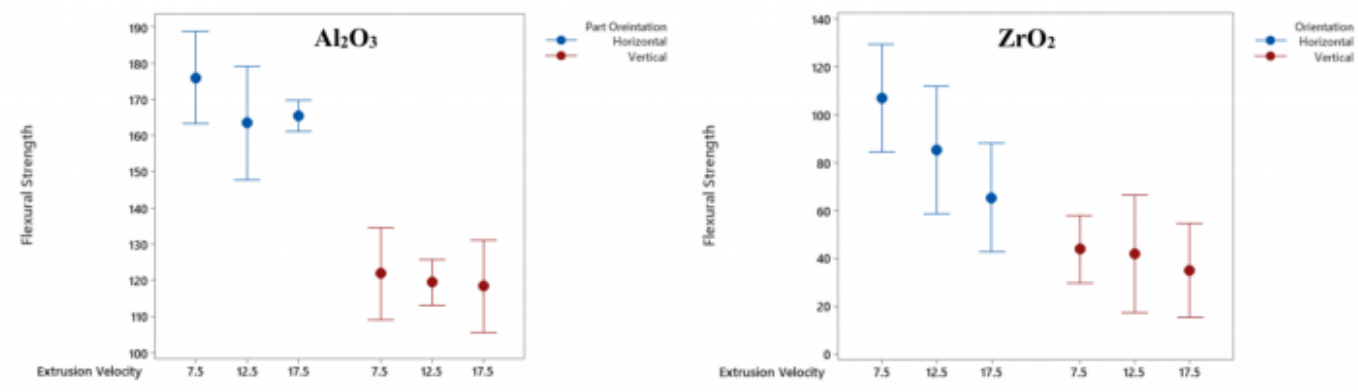

Fig. 8. Interval plots for both ceramics indicating the significance of horizontal orientation for flexural strength.

Since some applications of ceramics require high values of flexural strength so optimization can be achieved by printing the samples in horizontal printing orientation using extrusion-based additive manufacturing for maximizing the flexural strength of the ceramics. 
Optimization of process-property relations of 3D printed ceramics using extrusion-based...

\section{Conclusion}

Optimization of relations between extrusion-based 3D printing process parameters and mechanical properties of 3D printed ceramics (alumina and zirconia) was reported in this study. The process parameters selected were part orientation and extrusion velocity and the selected properties were microhardness and flexural strength. It was observed that the part orientation was the significant process parameter for microhardness for both ceramics. Additionally, the vertical orientation samples showed higher values of hardness as compared to their horizontal counterparts. The extrusion velocity had little to no effect on the microhardness for both ceramics. The microhardness could be optimized using vertical printing orientation as per the findings.

In the case of flexural strength, the horizontal orientation samples showed higher values as compared to their vertical counterparts. The extrusion velocity had little to no effect on the flexural strength of both ceramics just like in the case of microhardness and showed no clear trend. The flexural strength could be optimized using horizontal printing orientation. Furthermore, the optimization could also be achieved according to the application requirements of the ceramics. If high hardness is desirable for applications then the parts should be printed using vertical orientation and if high flexural strength is desirable for applications then parts should be printed using horizontal orientation as per the findings of this study.

\section{Bibliography}

[1] Z. Chen et al., "3D printing of ceramics: A review," Journal of the European Ceramic Society, vol. 39, no. 4, pp. 661-687, 2019/04/01/2019.

[2] A. Bellini, L. Shor, and S. Guceri, "New developments in fused deposition modeling of ceramics," Rapid Prototyping Journal, vol. 11, pp. 214-220, 09/01 2005.

[3] S. L. Sing et al., "Direct selective laser sintering and melting of ceramics: A review," Rapid Prototyping Journal, vol. 23, pp. 611-623, 09/01 2017.

[4] C. Piconi and G. Maccauro, "Zirconia as a ceramic biomaterial," (in eng), Biomaterials, vol. 20, no. 1, pp. 1-25, Jan 1999.

[5] D. W. Richerson, Modern Ceramic Engineering Properties, Processing, and Use in Design, 3rd ed. Boca Raton: CRC Press, 2005, p. 728 pages.

[6] R. H. D. James Shackelford, Ceramic and Glass Materials, 1 ed. Springer US, 2008, pp. XII, 202.

[7] W. Apholt, A. Bindl, H. Lüthy, and W. H. Mörmann, "Flexural strength of Cerec 2 machined and jointed InCeramAlumina and InCeram-Zirconia bars," (in eng), Dent Mater, vol. 17, no. 3, pp. 260-7, May 2001.

[8] A. Belenky and D. Rittel, "Static and dynamic flexural strength of 99.5\% alumina: Relation to porosity," Mechanics of Materials, vol. 48, pp. 43-55, 2012/05/01/ 2012.

[9] D. Ćorić, M. Majić Renjo, and L. Ćurković, "Vickers indentation fracture toughness of Y-TZP dental ceramics," International Journal of Refractory Metals and Hard Materials, vol. 64, pp. 14-19, 2017/04/01/ 2017.

[10] C. S. Gonzalez-Gutierrez J, Schuschnigg S, Kukla C, Sapkota J, Holzer C., "Additive Manufacturing of Metallic and Ceramic Components by the Material Extrusion of Highly-Filled Polymers: A Review and Future Perspectives.," Materials, vol. 11, no. 5, p. 840, 2018.

[11] K. Rane and M. Strano, "A comprehensive review of extrusion-based additive manufacturing processes for rapid 
production of metallic and ceramic parts," Advances in Manufacturing, vol. 7, no. 2, pp. 155-173, 2019/06/01 2019.

[12] M. Strano, K. Rane, G. Herve, and A. Tosi, "Determination of process induced dimensional variations of ceramic parts, 3d printed by extrusion of a powder- binder feedstock," Procedia Manufacturing, vol. 34, pp. 560-565, 2019/01/ $01 / 2019$.

[13] K. Rane, T. Barriere, and M. Strano, "Role of elongational viscosity of feedstock in extrusion-based additive manufacturing of powder-binder mixtures," The International Journal of Advanced Manufacturing Technology, vol. 107, no. 11, pp. 4389-4402, 2020/04/01 2020 .

PDF automatically generated on 2021-05-22 05:01:52

Article url: https://popups.uliege.be/esaform21/index.php?id=3723

published by ULiège Library in Open Access under the terms and conditions of the CC-BY License (https://creativecommons.org/licenses/by/4.0) 